\title{
Assessment, Prediction and Mapping of Noise Levels in Vellore City, India
}

https://doi.org/10.1515/noise-2019-0004

Received Mar 06, 2019; accepted Jun 18, 2019

\begin{abstract}
Present study focuses on measurement, prediction and mapping of noise levels in important places of Vellore city located in Tamil Nadu state, India. Weekday and weekend noise levels at six locations (S1 to S6) are recorded during morning, afternoon and evening times. Sampling locations includes educational (S1), commercial (S2 and S4), tourist and recreational (S3), and mixed (S5 and S6) zones. Assessment in Vellore city showed maximum $\mathrm{L}_{e q}$ level in S4 and S5 and lowest is recorded in $\mathrm{S} 3$ throughout the study. Highest $\mathrm{L}_{e q}$ levels are recorded in evening (57.52-78.41 dB(A)) and afternoon (58.76-76.39 $\mathrm{dB}(\mathrm{A})$ ) time during weekday and weekend, respectively. Along with $\mathrm{L}_{e q}$, noise descriptors are also included and discussed in this study. Weekend has higher mean value of TNI than Weekday. CoRTN model is employed to predict the $\mathrm{L}_{10}$ values. Results showed good performance of model with marginal difference between measured and predicted $\mathrm{L}_{10}$ levels. Further noise maps are created separately for weekday and weekend using ArcGIS software. Noise maps showed alarming noise levels near sampling sites and it is suggested to take immediate preventive measures using barriers or by providing alternative traffic routes.
\end{abstract}

Keywords: Urban noise, Noise model, Noise climate, Traffic noise index, CoRTN model

\footnotetext{
*Corresponding Author: B. Srimuruganandam: School of Civil Engineering, Vellore Institute of Technology (VIT), Vellore - 632 014, Tamil Nadu, India; Email: bsrimuruganandam@vit.ac.in; Tel.: 91-416-2202169; Fax: 91-416-2243092

N. Manojkumar: School of Civil Engineering, Vellore Institute of Technology (VIT), Vellore - 632 014, Tamil Nadu, India; Email: manojkumar.n2017@vitstudent.ac.in

Khadar Basha: School of Civil Engineering, Vellore Institute of Technology (VIT), Vellore - 632 014, Tamil Nadu, India
}

\section{Introduction}

Indian urban population is experiencing higher noise levels due to unprecedented vehicle growth and rapid infrastructure development [60]. Increasing noise levels in Indian cities can be related to sources like vehicular traffic, construction activities, industrial processes, spiritual celebrations and occasional fireworks [25, 67]. Noise propagation is dependent upon the urban structure viz. street profile, location of roads, distance of buildings from roads, construction sites, shape of the buildings and its orientation [26, 37]. Thus, it is evident that environmental noise varies spatially in urban area [38]. Earlier studies have reported about $80 \%$ of environmental noise is contributed by traffic $[21,58]$.

Globally in most part of urban centers, the noise sources are always close to receivers without any noise barriers. This leads to high level of noise exposure in the urban living community. The persistent higher levels of noise exposures are associated with physiological and other health effects $[5,7,44]$. Most common effects of ambient noise include interference in daily activities (sleep, speech, and work), annoyance, cognitive impairment, dementia, cardiovascular diseases, and respiratory diseases $[4,8,10]$. Noise pollution is found to be the major cause of environmental burden of disease next to air pollution [64]. Several studies are conducted earlier to assess the exposure and impact of noise on human health [19, 36, 48]. Some of the major findings are reported here. A very recent study by World Health organization (WHO) showed that 466 million people are suffering from disabling hearing loss at global level and in 2050 it is estimated about 900 million people i.e., 1 in every 10 people will be affected [65]. The total disability-adjusted life years due to ambient noise in European countries are estimated to be 1.6 million years [64]. European Environment Agency estimated the noise induced annual premature mortality to be 10,000 cases [20]. Whereas in the UK, the total cases attributed to noise-induced dementia, stroke and acute myocardial infarction are 1169, 788, and 542 cases. Also, monetary burden of all these cases is estimated to be 1.09 billion UK pound [27]. A recent study in Madrid, Spain observed that 1

Oopen Access. () 2019 N. Manojkumar et al., published by De Gruyter. (cc) BY 4.0 License 
$\mathrm{dB}(\mathrm{A})$ reduction in noise level would have avoided 184 premature respiratory deaths and 284 premature cardiovascular deaths [58].

Several models are developed and employed for predicting noise levels in the urban area. Widely adopted models include CoRTN (Calculation of Road Traffic Noise) model, Traffic Noise Model, FHWA (Federal Highway Administration), RLS 90 (Richtlinien für den Lärmschutz an Strassen), CadnaA (Computer Aided Noise Abatement), DYNAMAP (Dynamic Acoustic Mapping), and Acoustical Society of Japan model [32, 46, 51, 52]. Recently Melo et al. (2015) [35] investigated the adequacy of various models in predicting the traffic noise levels and concluded that CoRTN model, RLS 90, and models developed by Golmohammadi et al. (2009) and Da Paz and Zannin (2010) [16, 23] have showed best performance with minimal mean difference to measured values. Results from prediction models are extensively used for plotting noise maps and to compare the measured values. Noise map represent the noise levels in graphical format and is used frequently as a guide in urban noise management [3]. Noise mapping also helps in the estimation of environmental noise exposure in a particular location [11].

The noise pollution (regulation and control) rules of India are published in the year 2000 by Ministry of Environment, Forest and Climate Change - Government of India. The rule directs the state government to categorize the area into silence, residential, commercial and industrial zones. Industrial zone has the highest noise limits of 75/70 $\mathrm{dB}(\mathrm{A})$ during day/night time followed by $65 / 55 \mathrm{~dB}(\mathrm{~A})$ in commercial, 55/45 dB(A) in residential and 50/40 dB(A) in silence zone. The use of firecrackers, horns and construction equipment in night time are restricted in residential and silence zones. In addition to this, India has separate noise rules for vehicles, diesel generator set, fire crackers and air ports [15]. The noise limits specified by India are found to higher in all zones when compared with WHO noise guidelines [62]. European noise directive suggests dose-effect relations to assess human health effects. Further member states should create noise map for every five years to prepare the action plan [57]. In case of India no such rules exist for strategic noise mapping and assessing human health.

Although noise plays a significant role in environmental pollution, it has attracted very less attention in India. As per noise pollution (regulation and control) rules of India, the noise level in residential area should not exceed 55 and $45 \mathrm{~dB}(\mathrm{~A})$ during day and night time, respectively. But recent noise level assessment in Indian megacities showed an average of $80 \mathrm{~dB}(\mathrm{~A})$ [17]. Thus, it is clear that it is the right time for making amendments in noise limits and noise management plan. Before implementing the noise abatement plan, it is crucial to assess the noise levels [53]. Hence the study aims to assess ambient noise levels in Vellore city, one of the fast growing cities in Tamil Nadu, India. In addition to real-time noise level measurements, this study also evaluates the suitability of noise prediction model viz., CoRTN model. Further noise mapping is done by using ArcGIS software to estimate the environmental noise exposure levels in the study region.

\section{Methods}

\subsection{Site Characteristics and Sampling Protocol}

Vellore is one of the rapidly expanding Indian cites located in Tamil Nadu. As per the recent census report, Vellore urban agglomeration has a population of 4,84,690 lakh people in which the male and female population are 2,41,201 and 2,43,489 respectively [24]. The total number of commercial and non-commercial vehicles registered are found to be 2,021 and 24,452 respectively, between the year 2016 and 2017 [59]. Similar to other cities of India, the traffic in Vellore is mixed flow consisting of buses, trucks, cars, three-wheelers, and two-wheelers. Lane disciple is hard to follow in the city as the mixed traffic consists of vehicles traveling with different speeds and dimensions [6].

Sampling locations considered in this study are near Vellore Institute of Technology (VIT) (S1), near railway station (S2), Vellore fort (S3), new bus stand (S4), near CMC hospital (S5) and Gandhi Nagar (S6). All these six locations fall under following zones viz. educational (S1), commercial (S2, S4), recreational and tourist (S3), and mixed zone (S5 and S6). Location S5 consists of hospital and commercial zone whereas $\mathrm{S} 6$ has educational and residential zone. Sampling location coordinates and its respective zones are given in Table 1. In the present study, Sound level meter (Make: BSWA Technology Co., Ltd; Model: 308 class I) is used for logging parameters such as equivalent noise levels (Leq), minimum level with A-weighted frequency response and fast time constant $\left(\mathrm{LAF}_{\min }\right)$, maximum level with A-weighted frequency response and fast time constant $\left(\mathrm{LAF}_{\max }\right)$, noise level exceeded during 10\%, $50 \%, 90 \%$ and $99 \%$ of measurement period $\left(\mathrm{L}_{10}, \mathrm{~L}_{50}, \mathrm{~L}_{90}\right.$, and $\left.\mathrm{L}_{99}\right)$. Noise measurements are carried out in weekday (Monday to Friday) and weekend (Saturday to Sunday) during different times of the day viz., morning (07:0009:00 a.m.; 10:00 a.m.-12:00 p.m.), afternoon (12:0004:00 p.m.) and evening (05:00-08:00 p.m.). Data is 
Table 1: Sampling location and its characteristics

\begin{tabular}{ccccc}
\hline Location & Landmark & Latitude & Longitude & Zone \\
\hline S1 & Near VIT & 12.968245 & 79.155867 & Educational \\
S2 & Near Railway Station & 12.971634 & 79.137875 & Commercial \\
S3 & Vellore Fort & 12.920534 & 79.129028 & Tourist and recreational \\
S4 & Near Bus station & 12.934663 & 79.138785 & Commercial \\
S5 & Near CMC Hospital & 12.924565 & 79.133282 & Hospital and commercial \\
S6 & Gandhi Nagar & 12.954692 & 79.141700 & Educational and residential \\
\hline
\end{tabular}

logged every second in all sampling locations throughout the study (November 2018 to January 2019). The instrument is placed at a height of $1.2 \mathrm{~m}$ from ground surface to avoid the reflections from ground. The noise measurements are done within $7.5 \mathrm{~m}$ radius of selected sites where the sound influence would be more and without having any obstructions in the medium $[1,45,50]$.

\subsection{Calculation of Noise Climate, Traffic Noise Index, and Noise Pollution Level}

Noise climate (NC) is useful for analyzing the variation of sound levels in a given time period and calculated by deducting $\mathrm{L}_{90}$ from $\mathrm{L}_{10}$. Traffic noise index (TNI) is calculated based on the background $\left(\mathrm{L}_{10}\right)$ and highest $\left(\mathrm{L}_{90}\right)$ level recorded. The calculated TNI has a significant relationship with dissatisfaction of noise. Annoyance and discomforts such as sleep disturbance are accounted in TNI [30]. Noise pollution level $\left(\mathrm{L}_{n p}\right)$ is also calculated in this study. Equations for calculating NC, TNI, and $\mathrm{L}_{n p}$ are given in equations 1 to $4[14,28,49]$.

$$
\begin{gathered}
\mathrm{NC}=\mathrm{L}_{10}-\mathrm{L}_{90} \\
\mathrm{TNI}=4(\mathrm{NC})+\mathrm{L}_{90}-30 \\
\mathrm{~L}_{e q}=\left[\mathrm{NC}^{2} / 60\right]+\mathrm{L}_{50} \\
\mathrm{~L}_{n p}=\mathrm{NC}+\mathrm{L}_{e q}
\end{gathered}
$$

\subsection{CoRTN Model}

CoRTN model is adopted for predicting noise levels at S1, $\mathrm{S} 2, \mathrm{~S} 4, \mathrm{~S} 5$, and S6. The procedure of CoRTN model is developed for traffic noise estimation. This model predicts the Value of $\mathrm{L}_{10}$ on 1 hour or 18 hours of reference time for traffic with mean speed of $75 \mathrm{Km} / \mathrm{h}$. For running CoRTN model the essential input parameters are hourly traffic volume of heavy vehicles (bus and truck), percentage of heavy vehicles per hour, mean velocity of vehicles, gradient of the impervious bituminous road, corrected vehicle speed after gradient, shortest slant height distance, and basic noise emission level. An important correction factor with respect to vehicle speed should be applied for bituminous road with impervious surfaces i.e., $1 \mathrm{~dB}(\mathrm{~A})$ will be deducted if traffic speed is less than $75 \mathrm{Km} / \mathrm{h}$ and when speed is greater than or equal to $75 \mathrm{Km} / \mathrm{h}$, correction applied is based on texture depth of road. The updated CoRTN model has redefined the heavy vehicle by increasing the unladen weight to $3500 \mathrm{Kg}$ from $1525 \mathrm{Kg}$ [35]. Also, other correction factors viz., correction for the gradient, the angle of view, the distance between source and receiver, heavy vehicles related corrections are applied according to Vellore site conditions $[46,52]$. Values assigned for each input parameters and the results of correction factors are given in Supplementary Table S1.

\subsection{Noise Mapping}

Noise map is a cartographic representation of noise levels in defined area and specified time. So far noise maps are created for residential, educational, hospitals, roadway, airport areas in urban environment [13, 22, 41, 56, 61, 68]. Noise maps are also used for various evaluation viz., noise levels during different levels of any construction project and impact of new roadways/highways within urban limits. Thus, noise maps serves as useful strategic tool for environmental management decisions and urban planning $[12,66]$. Noise mapping for the present study is done using ArcGIS software (Version 10.1). Initially, the shapefile of Vellore city is created with the help of base map. This shapefile covers the important areas viz. residential, educational, commercial, and recreational places of the city. Then the excel file consisting of sampling points name, latitude, longitude, and average $\mathrm{L}_{e q}$ values (morning, afternoon and evening of weekday and weekend) recorded 


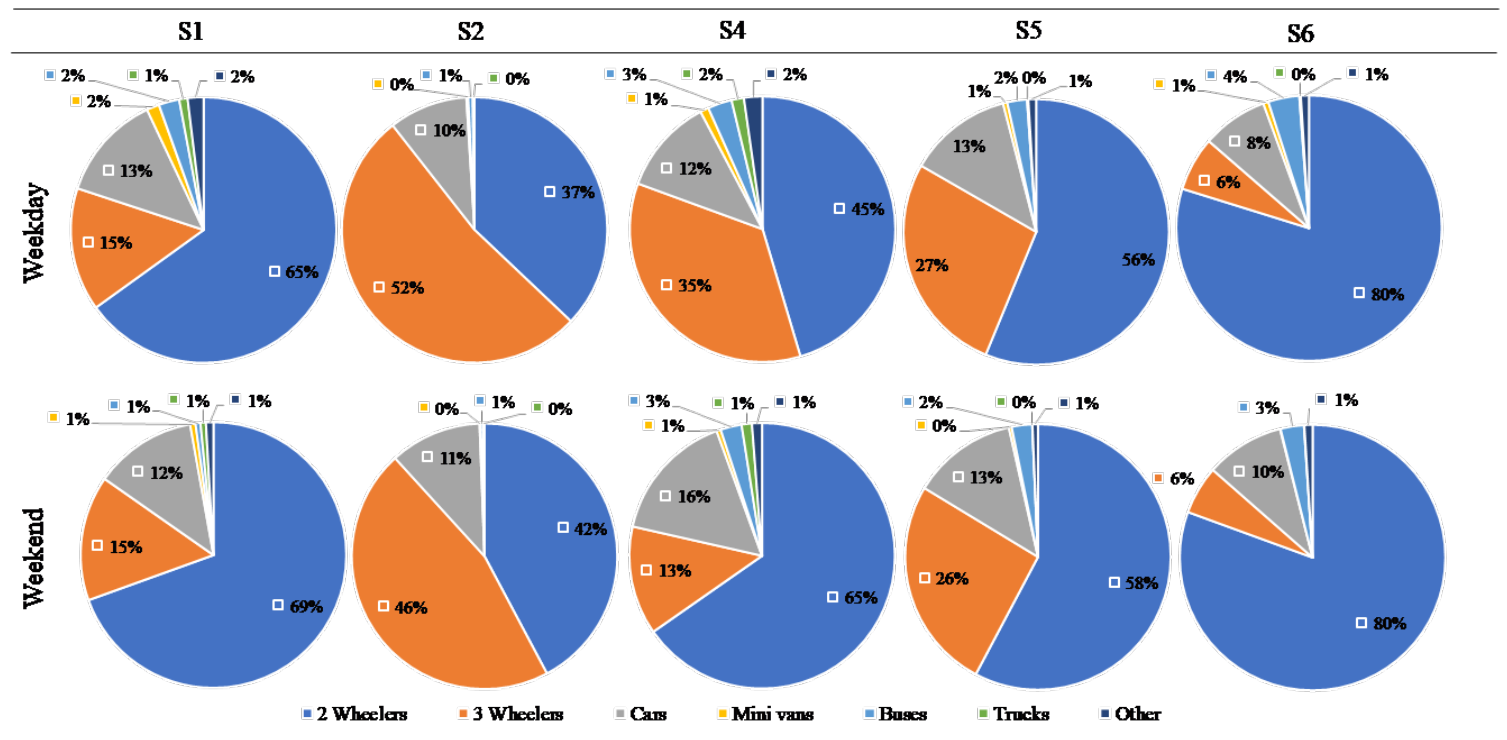

Figure 1: Vehicle composition at sampling locations

at each sampling site are imported into ArcGIS. After importing, sampling points will be plotted on the Vellore city shapefile. Now the noise level is visible only at six sampling points. Hence to identify noise levels at other places, interpolation method is used in this study [31,34].

\section{Results and Discussion}

\subsection{Vehicle Composition}

Vehicle composition is studied in all places except S3. Since $\mathrm{S} 3$ is a recreational and tourist spot, all vehicles are parked outside the fort premises. In other sites video cameras are used to record traffic flow during morning (07:0009:00 a.m.; 10:00-12:00 p.m.), afternoon (12:00-04:00 p.m.) and evening (05:00-08:00 p.m.) times. The recorded video is manually reviewed for quantifying traffic volume contributed by different type of vehicles viz., two wheelers (bikes and scooters), three wheelers (auto rickshaws), cars, mini vans, buses, trucks, and other vehicles (pickup vans and tractors). The vehicle composition in each sampling location is given in Figure 1. Except S2, all other sampling spots are dominated by two-wheeler movements. S6 being mixed zone (residential and educational) has highest twowheeler movement in both weekdays and weekdays. Next to S6, site S1 has high two-wheeler movements due to presence of educational institution. It is also observed that twowheeler contribution is high during weekend than weekday. In S2, three wheelers (auto-rickshaws) contribute 52\% and $46 \%$ of traffic volume during weekday and weekend.
The lowest three wheelers movement is recorded in S6 location. In other sampling locations (S1, S4 and S5) the three-wheeler contribution ranges from 15 to $35 \%$ in weekday and 15 to $26 \%$ in weekend. About $80 \%$ of traffic volume is contributed by two-wheelers and three-wheelers in all sampling points. Cars have substantial contribution of $8-13 \%$ in weekday and $10-16 \%$ in weekend to total traffic volume. Cars movement is more or less equal in weekend when compared to weekday. Locations S1 and S3 are identified with minimal truck movement whereas S2, S5 and S6 have no truck movement. Likewise, bus movements are identified in all locations except S2 location. Vehicles like minivans, buses, and trucks have minimum contribution to total traffic volume in all study locations.

\subsection{Leq Levels Measured at Six Sampling Locations}

Average $\mathrm{L}_{e q}$ measured at six locations are given in Supplementary Table S2. As per the Indian noise standards, measured values are segregated into four ranges viz. Range 1 ( $\leq 55 \mathrm{~dB}(\mathrm{~A})$ ), Range $2(>55, \leq 65 \mathrm{~dB}(\mathrm{~A}))$, Range $3(>65, \leq$ $75 \mathrm{~dB}(\mathrm{~A}))$ and Range 4 (>75 dB(A)). The percentage of measured values in each range for the corresponding location is given in Table 2. Measurements in S5 and S4 showed that all values are exceeding $65 \mathrm{~dB}(\mathrm{~A})$. In these sample places, it is also observed that more than $60 \%$ of measured values are $>75 \mathrm{~dB}(\mathrm{~A})$. Sampling stations such as S1 and S2 have $60-70 \%$ of their values in the Range 3. Locations S3 and S6 are the only two places recorded the values below $55 \mathrm{~dB}(\mathrm{~A})$. 
Table 2: Categorization of measured Leq values

\begin{tabular}{ccccccccccccc}
\hline Leq & \multicolumn{2}{c}{ S1 } & \multicolumn{2}{c}{ S2 } & \multicolumn{2}{c}{ S3 } & \multicolumn{2}{c}{ S4 } & \multicolumn{3}{c}{ S5 } & \multicolumn{2}{c}{ S6 } \\
\cline { 2 - 12 } (dB(A)) & WD & WE & WD & WE & WD & WE & WD & WE & WD & WE & WD & WE \\
\hline Range 1 ( $\leq 55)$ & - & - & - & - & 35 & 30 & - & - & - & - & 3 & 2 \\
Range 2 $(>55, \leq 65)$ & 36 & 23 & 26 & 23 & 61 & 52 & - & - & - & - & 39 & 36 \\
Range 3 $(>65, \leq 75)$ & 60 & 70 & 68 & 69 & 4 & 18 & 39 & 63 & 26 & 52 & 51 & 54 \\
Range 4 $(>75)$ & 4 & 7 & 6 & 7 & - & 1 & 61 & 37 & 74 & 48 & 7 & 7 \\
\hline
\end{tabular}

Note: All values are in $\%, \mathrm{WD}=$ Weekday, $\mathrm{WE}=$ Weekend

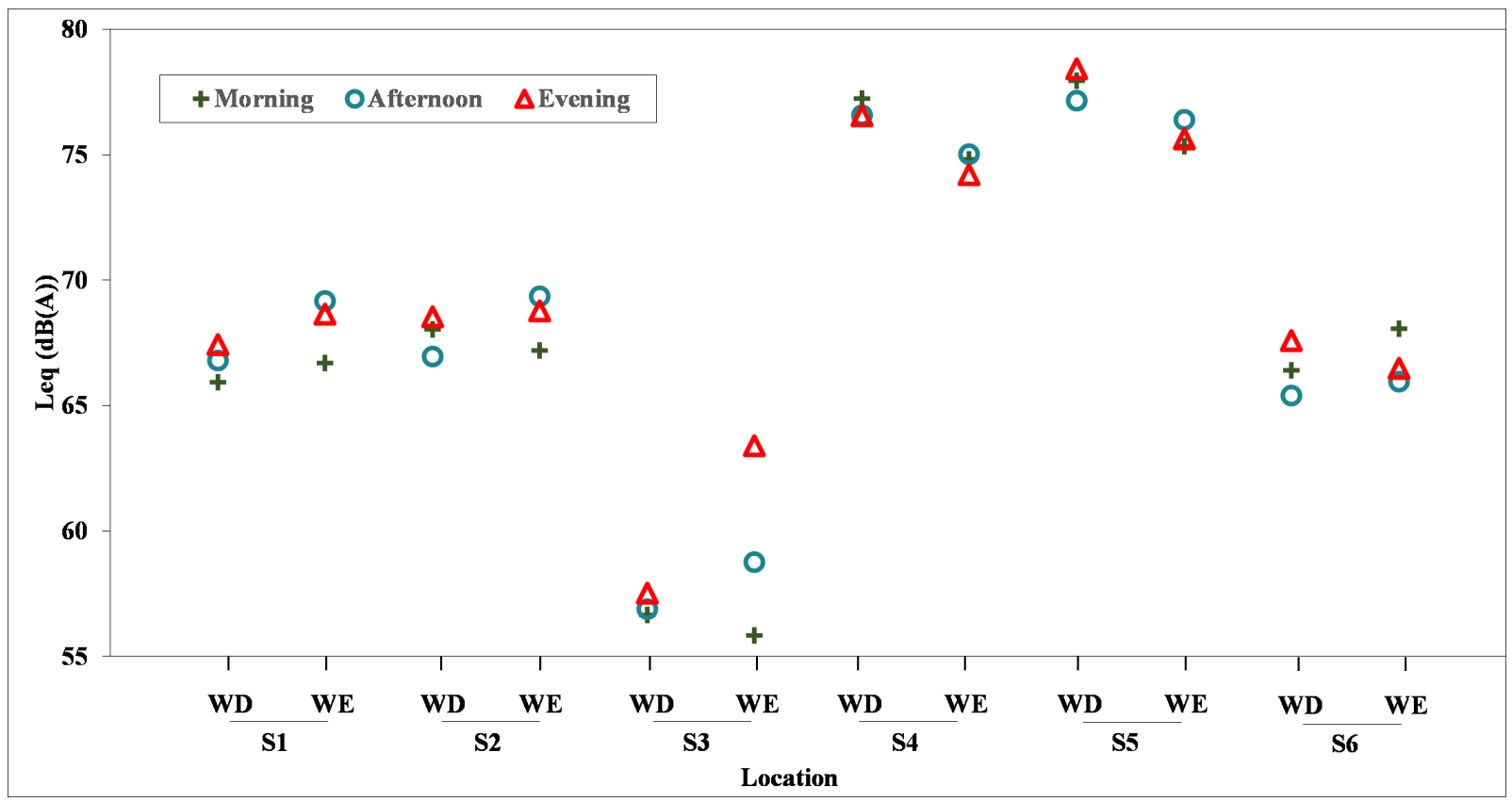

Figure 2: Leq measured during different times of the day

Vellore Fort has 35\% and 30\% of measured noise levels in Range 1 during weekday and weekend, respectively.

Weekday and weekend noise levels at six locations are recorded during morning, afternoon and evening times. Average Leq levels recorded at each sampling sites are plotted in Figure 2. In weekday morning and evening, the maximum to minimum average values are in the order of $\mathrm{S} 5>\mathrm{S} 4>\mathrm{S} 2>\mathrm{S} 6>\mathrm{S} 1>\mathrm{S} 3$. Same in weekday afternoon is found to have $\mathrm{S} 5>\mathrm{S} 4>\mathrm{S} 2>\mathrm{S} 1>\mathrm{S} 6>\mathrm{S} 3$. Further S5 and S4 are the two places recorded with highest Leq average values. In weekday, S5 place has maximum Leq in the evening (78.4 4 4.4 $\mathrm{dB}(\mathrm{A}))$, followed by morning $(77.9 \pm 4.1 \mathrm{~dB}(\mathrm{~A}))$ and afternoon $(77.1 \pm 4.4 \mathrm{~dB}(\mathrm{~A}))$. The measured values at $\mathrm{S} 4$ are close to the values recorded in S5. Except S4, all other sampling points are found to have the highest values in evening time.

During the weekends, the places with maximum to minimum average values for morning is observed in the order of $\mathrm{S} 5>\mathrm{S} 4>\mathrm{S} 6>\mathrm{S} 2>\mathrm{S} 1>\mathrm{S} 3$. In case of afternoon and evening the order changed to $\mathrm{S} 5>\mathrm{S} 4>\mathrm{S} 2>\mathrm{S} 1>\mathrm{S} 6>\mathrm{S} 3$. Similar to weekdays, $\mathrm{S} 5$ has maximum weekend average values of $75.3 \pm 4.4 \mathrm{~dB}(\mathrm{~A}), 76.3 \pm 4.6 \mathrm{~dB}(\mathrm{~A})$ and $75.6 \pm 4.5 \mathrm{~dB}(\mathrm{~A})$ in the morning, afternoon and evening, respectively. Sampling points $\mathrm{S} 4$ and $\mathrm{S} 6$ are recorded with maximum levels in the morning time. Same with S1, S2, S3, and S5 have high Leq values in the evening. The noise limits (for day time: 06:00 a.m. to 10:00 p.m.) as per Indian government in commercial, residential and silence zone are 65,55 , and $50 \mathrm{~dB}(\mathrm{~A})$, respectively. It is observed that all the values from the present study have violated the Indian standard noise levels.

A study in the municipality of Malda, West Bengal, India recorded a maximum mean value of $44 \mathrm{~dB}(\mathrm{~A})$ in residential, $52 \mathrm{~dB}(\mathrm{~A})$ in commercial, and $57 \mathrm{~dB}(\mathrm{~A})$ in heavy traffic congestion [17]. Average noise level in Santiago, Chile is measured in different road categories and it ranges between 61.2 and $73.3 \mathrm{~dB}(\mathrm{~A})$ [53]. A similar study in Valdivia, Chile has maximum and minimum of 58.5 and $73.7 \mathrm{~dB}(\mathrm{~A})$, 


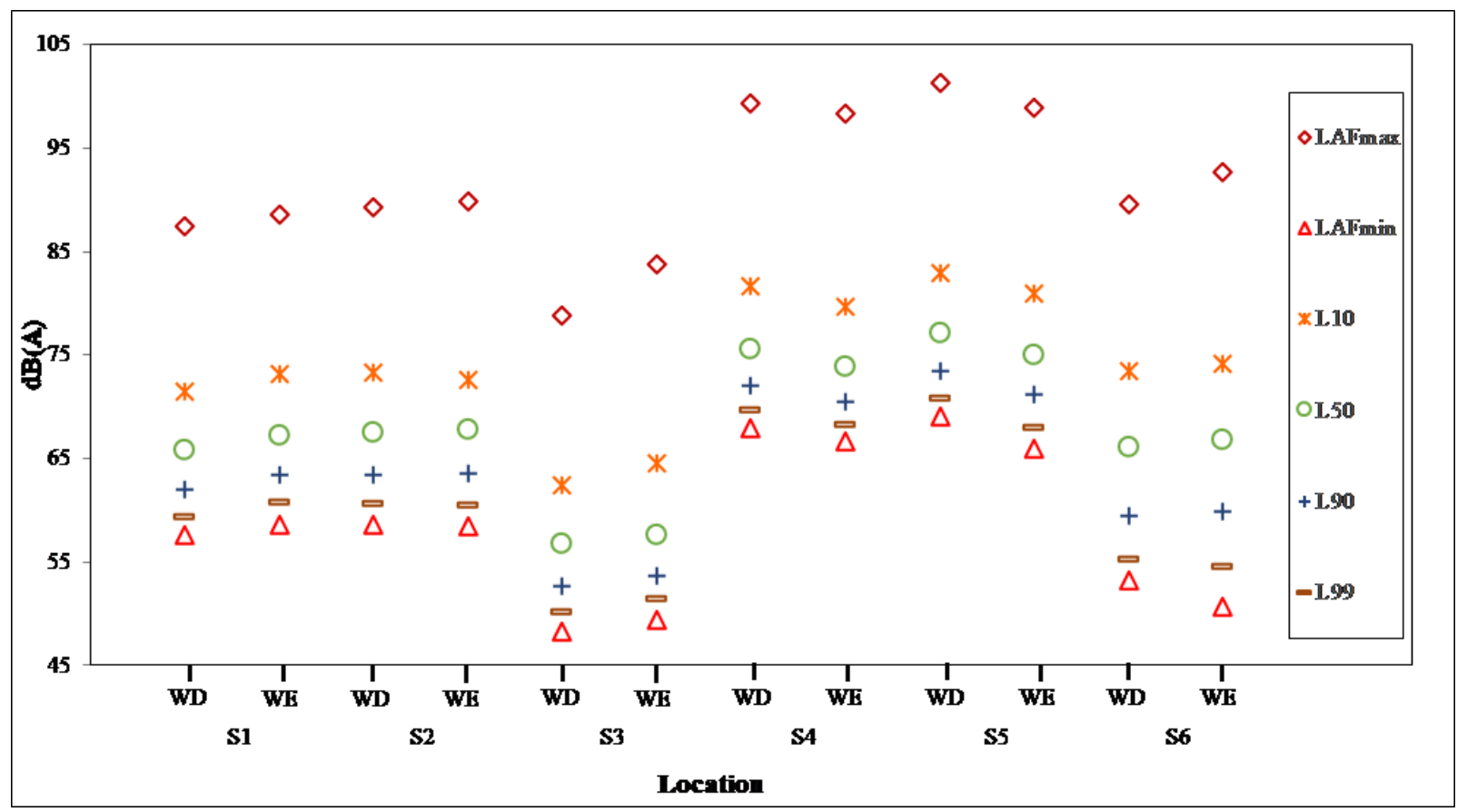

Note: WD-Weekday, WE-Weekend

Figure 3: Noise descriptor levels during weekday and weekend

Table 3: Summary of independent t-test

\begin{tabular}{ccccc}
\hline Location & $\begin{array}{c}\text { Mean } \\
\text { Difference }\end{array}$ & \multicolumn{2}{c}{$\begin{array}{c}\text { 95\% Confidence } \\
\text { Interval of the } \\
\text { Difference }\end{array}$} & P value \\
\cline { 3 - 4 } & & \multicolumn{2}{c}{ Lower } & Upper \\
\hline S1 & 1.61 & 1.55 & 1.67 & $<0.05$ \\
S2 & 0.38 & 0.31 & 0.45 & $<0.05$ \\
S3 & 2.11 & 2.03 & 2.18 & $<0.05$ \\
S4 & 2.14 & 2.21 & 2.08 & $<0.05$ \\
S5 & 2.16 & 2.22 & 2.10 & $<0.05$ \\
S6 & 0.43 & 0.34 & 0.52 & $<0.05$ \\
\hline
\end{tabular}

respectively [9]. Leq measurements inside Greek hospital premises showed the values between 55 and $80 \mathrm{~dB}(\mathrm{~A})$ [33]. Another study, developed in São Paulo, Brazil, found measured values of equivalent sound pressure level, similar to the equivalent sound levels measured in the present study [42].

\subsection{Statistical Analysis of Weekday and Weekend Data}

The statistical tools available for mean tests are one-way ANOVA and independent t-test. One-way ANOVA can only be performed if three variables are available. But the present study has only two variables, i.e., weekday and weekend data. Hence independent t-test is performed by comparing the means of weekday and weekend values. Using IBM-SPSS Statistics software (Version 23), the mean difference, lower and upper bound values with 95\% confidence interval and significance (P value) are estimated. The results of this test are presented in Table 3. It is observed that S2 and S6 points have marginal mean difference whereas other sampling points are observed between 1.61-2.16. However, the $\mathrm{P}$ value in all six places is found to be less than 0.05 . This shows there is a significant difference between weekday and weekend noise levels, and it is mainly due to weekday and weekend variation in traffic.

\subsection{Noise Descriptors}

The average of all noise descriptors is plotted and presented in Figure 3. Station S5 has the highest values of $\mathrm{LAF}_{\text {max }}$ and $\mathrm{LAF}_{\text {min }}$ in both weekday and weekend. Likewise, the lowest $\mathrm{LAF}_{\text {max }}$ and $\mathrm{LAF}_{\text {min }}$ are recorded in S3. Highest $\mathrm{LAF}_{\text {max }}$ and lowest $\mathrm{LAF}_{\text {min }}$ values are recorded in $\mathrm{S} 5(101.25 \mathrm{~dB}(\mathrm{~A}))$ and $\mathrm{S} 3(48.29 \mathrm{~dB}(\mathrm{~A}))$, respectively. It is surprising to note that even $\mathrm{LAF}_{\text {min }}$ has violated the Indian standards in places like silent zone (S1) and commercial zone (S4). In the evenings of weekday, the S1, S2, 
Table 4: Summary of noise descriptors

\begin{tabular}{cccccccc}
\hline Place & Time & \multicolumn{2}{c}{ Noise climate } & \multicolumn{2}{c}{ Noise pollution level } & \multicolumn{2}{c}{ Traffic noise index } \\
\cline { 3 - 7 } & & WD & WE & WD & WE & WD & WE \\
\hline S1 & Morning & 9.92 & 8.89 & 76.73 & 76.08 & 70.55 & 67.64 \\
& Afternoon & 8.97 & 10.79 & 76.13 & 80.81 & 68.24 & 77.17 \\
& Evening & 9.90 & 9.35 & 78.07 & 78.61 & 72.32 & 71.56 \\
\hline S2 & Morning & 9.80 & 9.80 & 79.53 & 78.64 & 72.92 & 72.11 \\
& Afternoon & 9.26 & 10.44 & 76.69 & 80.39 & 68.59 & 75.84 \\
& Evening & 8.86 & 8.94 & 78.59 & 78.82 & 69.87 & 70.20 \\
\hline S3 & Morning & 10.37 & 10.84 & 68.48 & 67.57 & 63.13 & 64.68 \\
& Afternoon & 10.17 & 10.45 & 68.02 & 69.20 & 62.77 & 65.00 \\
& Evening & 8.19 & 11.64 & 67.85 & 78.34 & 58.03 & 75.77 \\
\hline S4 & Morning & 10.07 & 9.42 & 87.71 & 84.69 & 82.48 & 78.16 \\
& Afternoon & 10.07 & 8.89 & 87.10 & 84.04 & 82.05 & 75.99 \\
& Evening & 8.64 & 8.59 & 85.00 & 83.84 & 76.57 & 75.30 \\
\hline S5 & Morning & 9.27 & 9.72 & 87.73 & 86.06 & 80.36 & 79.80 \\
& Afternoon & 9.36 & 9.30 & 87.77 & 85.74 & 80.59 & 78.57 \\
& Evening & 9.48 & 10.30 & 87.69 & 87.01 & 81.12 & 82.28 \\
\hline S6 & Morning & 15.08 & 13.05 & 84.45 & 83.97 & 88.84 & 84.50 \\
& Afternoon & 13.89 & 14.22 & 82.65 & 84.52 & 84.39 & 86.58 \\
& Evening & 12.79 & 14.45 & 82.66 & 83.89 & 82.39 & 87.32 \\
\hline
\end{tabular}

Note: All values are given in $\mathrm{dB}(\mathrm{A})$

and $\mathrm{S} 3$ stations are found to have a maximum $\mathrm{LAF}_{\max }$. Other stations are found to have maximum $\mathrm{LAF}_{\text {max }}$ during morning (S6) and afternoon (S4 and S5). With respect to $\mathrm{LAF}_{\text {min }}$, all the places are observed to have maximum levels during evening. The highest $\mathrm{LAF}_{\max }(101.69 \mathrm{~dB}(\mathrm{~A}))$ and $\mathrm{LAF}_{\text {min }}(69.33 \mathrm{~dB}(\mathrm{~A}))$ are recorded respectively in $\mathrm{S} 6$ during afternoon and evening. In case of weekend, most of the sampling stations (S3, S4 and S6) are found to have maximum $\mathrm{LAF}_{\text {max }}$ in evening and few in afternoon $(\mathrm{S} 1, \mathrm{~S} 5)$ and morning (S2). The highest $\mathrm{LAF}_{\max }(99.05 \mathrm{~dB}(\mathrm{~A}))$ and $\mathrm{LAF}_{\text {min }}(66.89 \mathrm{~dB}(\mathrm{~A}))$ are observed in $\mathrm{S} 5$ and $\mathrm{S} 4$, respectively. Present study results are comparable with earlier reported values of hourly LAF $\max (78.6-102.4 \mathrm{~dB}(\mathrm{~A})$ ) in Sanandaj, Iran [39].

Statistical noise levels such as $\mathrm{L}_{10}, \mathrm{~L}_{50}, \mathrm{~L}_{90}$, and $\mathrm{L}_{99}$ are also assessed in six sampling locations. Maximum statistical noise levels in weekday and weekend are observed in S5 whereas minimum levels are recorded in S3 sampling point. The $\mathrm{L}_{10}$ values in present study (considering weekday and weekend) range from 62.41-82.84 $\mathrm{dB}(\mathrm{A})$. A study in Kota city of Rajasthan district, India has reported the $\mathrm{L}_{10}$ values between 52 and $77.9 \mathrm{~dB}(\mathrm{~A})$ [49]. Another study at Angul city, India reported variation of $\mathrm{L}_{10}$ from 91.6 to 95.6 $\mathrm{dB}(\mathrm{A})$ [2]. The average $\mathrm{L}_{90}$ value in weekday and weekend are 63.80 and $63.66 \mathrm{~dB}(\mathrm{~A})$, respectively. Similar values are reported earlier at Al-Samawah City, Iraq where $\mathrm{L}_{90}$ values in silent, commercial and industrial zones are exceeding $60 \mathrm{~dB}(\mathrm{~A})$ [47]. The range of $\mathrm{L}_{50}$ in present study is found to be $56.69-77.12 \mathrm{~dB}(\mathrm{~A})$. Earlier study in Jaipur showed $\mathrm{L}_{50}$ values between 68.60 and $77.90 \mathrm{~dB}(\mathrm{~A})$ [1]. In weekday, most of sampling points ( $\mathrm{S} 1, \mathrm{~S} 3, \mathrm{~S} 5$ and $\mathrm{S} 6$ ) have maximum statistical noise levels during evening time. But during weekend the maximum levels are recorded in morning (S4 and S6), afternoon (S1 and S2) and evening (S3 and S5). Recent studies at various cities of India and Bosnia showed the maximum levels during different times of the day viz., morning, afternoon and evening [18, 29, 54].

Estimated NC, TNI and $\mathrm{L}_{n p}$ values during different time of the day are presented in Table 4. The mean NC in weekday and weekend are calculated as 10.23 and 10.50 $\mathrm{dB}(\mathrm{A})$, respectively. The peak NC is observed during weekday morning and weekend evening at S6 location. In weekday, the lower NC values $(<9)$ are recorded in afternoon (S1) and evening (S2, S3 and S4), whereas in weekend it is observed in morning (S1), afternoon (S4), and evening (S2 and S4). NC from 5.8 to 30 are recorded in previous studies [43, 55]. TNI has the range of 58.03-88.84 dB(A) during weekday whereas, in weekend, these values are between 64.6-87.3 $\mathrm{dB}(\mathrm{A})$, respectively. This high TNI may result from overcrowded roads and minimal traffic management. Peak TNI values in morning, afternoon, and evening at sampling point S6 in both weekday and weekend. The 
Table 5: Measured and predicted values of noise level at sampling locations

\begin{tabular}{ccccccccccc}
\hline & \multicolumn{2}{c}{ S1 } & \multicolumn{2}{c}{ S2 } & \multicolumn{2}{c}{ S4 } & \multicolumn{2}{c}{ 55 } & \multicolumn{3}{c}{ S6 } \\
\cline { 2 - 12 } Weekday & $\mathbf{P}$ & $\mathbf{M}$ & $\mathbf{P}$ & $\mathbf{M}$ & $\mathbf{P}$ & $\mathbf{M}$ & $\mathbf{P}$ & $\mathbf{M}$ & $\mathbf{P}$ & $\mathbf{M}$ \\
\hline Morning & 75.09 & 71.23 & 72.39 & 73.00 & 80.21 & 81.67 & 81.59 & 83.08 & 75.67 & 74.03 \\
Afternoon & 76.73 & 72.87 & 70.46 & 70.91 & 80.66 & 81.11 & 82.32 & 82.50 & 74.91 & 73.58 \\
Evening & 74.51 & 70.89 & 69.25 & 71.73 & 79.44 & 81.33 & 80.08 & 83.05 & 73.33 & 73.01 \\
\hline Weekend & $\mathbf{P}$ & $\mathbf{M}$ & $\mathbf{P}$ & $\mathbf{M}$ & $\mathbf{P}$ & $\mathbf{M}$ & $\mathbf{P}$ & $\mathbf{M}$ & $\mathbf{P}$ & $\mathbf{M}$ \\
\hline Morning & 75.08 & 70.57 & 70.23 & 73.43 & 80.35 & 80.06 & 82.70 & 81.23 & 76.06 & 74.85 \\
Afternoon & 76.73 & 73.51 & 68.53 & 72.79 & 78.77 & 78.62 & 82.31 & 81.03 & 75.98 & 74.36 \\
Evening & 74.51 & 71.67 & 66.90 & 70.12 & 79.82 & 79.83 & 80.55 & 80.58 & 75.43 & 74.41 \\
\hline
\end{tabular}

Note: All values are given in $\mathrm{dB}(\mathrm{A}), \mathrm{P}=$ Predicted values, $\mathrm{M}=$ Measured values

lowest TNI in weekday (58.03 dB(A)) and weekend (64.68 $\mathrm{dB}(\mathrm{A})$ ) are recorded at $\mathrm{S} 3$ station. Similar TNI results are reported in earlier studies $[1,40]$. The average $\mathrm{L}_{n p}$ values in weekday and weekend are almost equal (80.16 and 80.68 $\mathrm{dB}(\mathrm{A})$ ). The range $\mathrm{L}_{n p}$ values range from 67.85 to $87.77 \mathrm{~dB}(\mathrm{~A})$ in weekday and 67.75 to $87.01 \mathrm{~dB}(\mathrm{~A})$ in weekend. Location S5 has highest average $\mathrm{L}_{n p}$ of 87 and $86 \mathrm{~dB}(\mathrm{~A})$ during weekday and weekend, respectively.

\subsection{CoRTN Results}

Predicted results at each sampling points are given in Table 5. CoRTN model performs well with all the measured data sets of study region, particularly on S4 weekend. In S1, the maximum differences between the measured and predicted values are $3.8 \mathrm{~dB}(\mathrm{~A})$ in the weekday and $4.5 \mathrm{~dB}(\mathrm{~A})$ in the weekend. Thus, results confirm that CoRTN model performs well in S2 (only weekday), S4, S5, and S6 locations with a marginal difference. However, in $\mathrm{S} 1$ the difference between predicted and measured noise levels varied from 3.6 to $3.8 \mathrm{~dB}(\mathrm{~A})$ in weekday and 2.8-4.5 $\mathrm{dB}(\mathrm{A})$ in weekend. In the case of $S 2$ weekend, the difference is recorded between 3.2 and $4.2 \mathrm{~dB}(\mathrm{~A})$. CoRTN performed well with weekday than weekend data. An average of $1.77 \mathrm{~dB}(\mathrm{~A})$ difference is seen in weekday whereas $1.89 \mathrm{~dB}(\mathrm{~A})$ in weekend. The CoRTN is assessed for the performance in morning, afternoon and evening data. It is found that weekday-afternoon has the best performance by having the lowest difference values of $0.18 \mathrm{~dB}(\mathrm{~A})(\mathrm{S} 5)$ and $0.45 \mathrm{~dB}(\mathrm{~A})$ (S2 and S3). Similarly the weekend-evening has the lowest difference values of $0.01 \mathrm{~dB}(\mathrm{~A})$ (S4) and $0.04 \mathrm{~dB}(\mathrm{~A})$ (S5). Overall the CoRTN model has performed well in the study region. The predicted values in Sao Paulo, Brazil ranges from 70 to 81.1 $\mathrm{dB}(\mathrm{A})$ with a difference of 0.8 to $3.5 \mathrm{~dB}(\mathrm{~A})$ [42]. Previous studies have shown a difference of $3.1 \mathrm{~dB}(\mathrm{~A})$ using SoundPLAN software [26]. Also the average difference of mea- sured and predicted noise levels in Santiago, Chile showed a range between 1.5-3.1 $\mathrm{dB}(\mathrm{A})$ [53]. Noise prediction in different road categories recorded a difference from 1.9 to 4.9 $\mathrm{dB}(\mathrm{A})[9]$.

\subsection{Noise Mapping}

Using Inverse Distance Weighting (IDW) the noise maps are created separately for different time periods of weekday and weekend. IDW is used for interpolating the known set of point values. The unknown point values are calculated based on the weighted average of known point values. Noise maps created after interpolation is presented in Figure 4. All created maps are assigned with same symbology for comparison and discussion. From Figure 4, it is clear that both weekday and weekend are covered largely by $66-70 \mathrm{~dB}(\mathrm{~A})$. Sampling sites S1, S2, and S6 are observed to have range of $64-70 \mathrm{~dB}(\mathrm{~A})$ in weekday and weekend. In weekday, $74-80 \mathrm{~dB}(\mathrm{~A})$ range is dominantly located near $\mathrm{S4}$ and S5. Areas around S4 and S5 are observed to have high noise level in weekday (74-80 $\mathrm{dB}(\mathrm{A}))$ and weekend (72-76 $\mathrm{dB}(\mathrm{A})$ ). Hence necessary noise abatement actions should be taken immediately.

\section{Conclusion}

Noise pollution in urban area is inevitable. Thus, it is crucial to assess noise levels in urban areas. Vellore is a fastgrowing city located in the state of Tamil Nadu, India. This study aims to measure $\mathrm{L}_{e q}, \mathrm{LAF}_{\text {min }}, \mathrm{LAF}_{\text {max }}, \mathrm{L}_{10}, \mathrm{~L}_{50}, \mathrm{~L}_{90}$, and $\mathrm{L}_{99}$ in important places of Vellore city. Sampling is taken in morning, afternoon and evening time on both weekday and weekend. Results showed that except the study site S3, all other sites are observed to have $\mathrm{L}_{e q}$ values higher than $65 \mathrm{~dB}(\mathrm{~A})$. As $\mathrm{S} 3$ site has nil traffic flow 


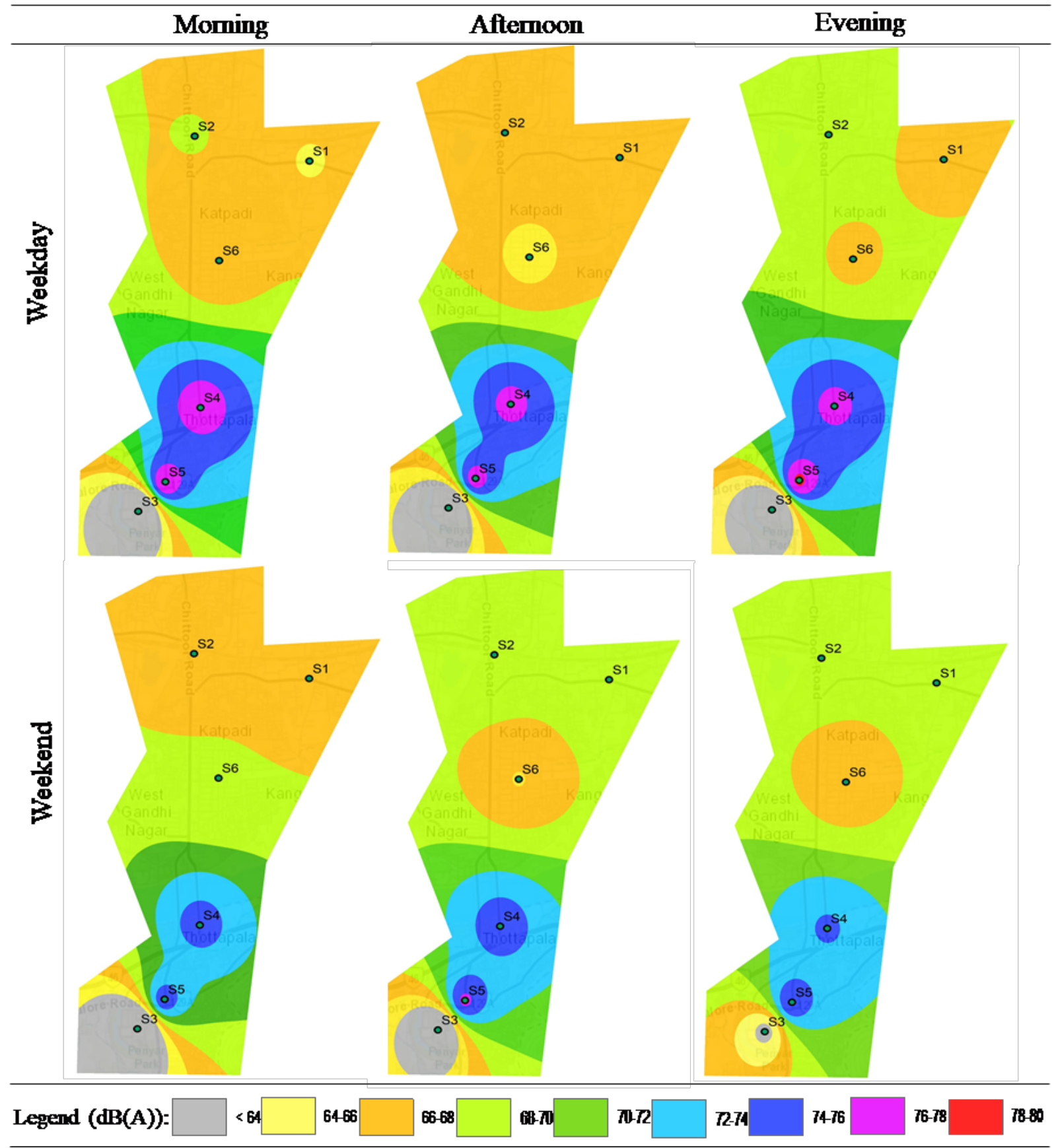

Note: Base map of Vellore city is shown in Supplementary Figure S1.

Figure 4: Noise map of Vellore City

it is recorded with lowest average values between 55.81 and $63.39 \mathrm{~dB}(\mathrm{~A})$. Sampling sites S4 and S5 are recorded with maximum values in morning, afternoon and evening. CoRTN model is utilized in the present study for predicting $\mathrm{L}_{10}$. Average difference between predicted and measured values is found to be $1.77 \mathrm{~dB}(\mathrm{~A})$ in weekday and $1.89 \mathrm{~dB}(\mathrm{~A})$ in weekend. Further noise maps for weekday and weekend are created in ArcGIS software using the average values recorded in six places. It is found that most of the places the noise levels are exceeding the stipulated Indian noise standards. In India, the lowest noise limits are set to 45 $\mathrm{dB}(\mathrm{A})$. But a recent study by WHO stated that noise level greater than $40 \mathrm{~dB}(\mathrm{~A})$ could cause notable health effects [63]. In India, the noise rule is enforced in the year 2000, and after that, no amendments are made by the Central Pollution Control Board. Hence this study has highlighted 
the urgent need of revising the noise guidelines and standard for healthier living in the urban area of India.

Funding: This research did not receive any specific grant from funding agencies in the public, commercial, or notfor-profit sectors.

Conflict of Interests: The authors declare no conflict of interest

\section{References}

[1] Agarwal, S., \& Swami, B. L. (2011). Comprehensive approach for the development of traffic noise prediction model for Jaipur city. Environmental Monitoring Assessment, 113-120. doi: 10.1007/s10661-010-1320-z

[2] Akula, C., Bijay, K., \& Goswami, S. (2012). Measurements and model calibration of traffic noise pollution of an industrial and intermediate city of India. The Ecoscan, 1, 377-386.

[3] Alam, S., Corcoran, L., King, E. A., Mcnabola, A., \& Pilla, F. (2017). Modelling of intra-urban variability of prevailing ambient noise at different temporal resolution. Noise mapping, 20-44. doi: 10.1515/noise-2017-0002

[4] Andersson, J., Oudin, A., Sundström, A., Forsberg, B., Adolfsson, R., \& Nordin, M. (2018). Road traffic noise, air pollution, and risk of dementia - results from the Betula project. Environmental Research, 166(February), 334-339. doi: 10.1016/j.envres.2018.06.008

[5] Arana, M., Martin, R. S., \& Salinas, J. C. (2014). People exposed to traffic noise in european agglomerations from noise maps. A critical review. Noise Mapping, 40-49. doi: 10.2478/noise-20140005

[6] Arasan, V. T., \& Dhivya, G. (2008). Measuring Heterogeneous Traffic Density. World Academy of Science, Engineering and Technology, 2(10), 236-240. doi.org/10.5281/zenodo.1070897

[7] Baliatsas, C., Kamp, V. ., Poll, V., \& Yzermans, J. (2016). Health effects from low-frequency noise and infrasound in the general population : Is it time to listen? A systematic review of observational studies. Science of the Total Environment, 557, 163-169. doi: 10.1016/j.scitotenv.2016.03.065.

[8] Baqar, M., Arslan, M., Abbasi, S. A., Ashraf, U., \& Zahid, H. (2017). Noise Pollution in the Hospital Environment of a Developing Country : A Case Study of Lahore. Archives of Environmental \& Occupational Health, (August), 1-8. doi: 10.1080/19338244.2017.1371106

[9] Bastián-Monarca, N. A., Suárez, E., \& Arenas, J. P. (2016). Assessment of methods for simplified traffic noise mapping of small cities : Casework of the city of Valdivia, Chile. Science of the Total Environment, 550, 439-448. doi: 10.1016/j.scitotenv.2016.01.139

[10] Belojevic, G., Jakovljevic, B., Stojanov, V., Paunovic, K., \& Ilic, J. (2008). Urban road-traffic noise and blood pressure and heart rate in preschool children. Environment International, 34, 226231. doi: 10.1016/j.envint.2007.08.003

[11] Borelli, D., Repetto, S., \& Schenone, C. (2014). Noise Mapping of the Flyover Highway in Genoa : comparison of different methods.
Noise mapping, 59-73. doi: 10.2478/noise-2014-0007

[12] Bravo-Moncayo, L., Chávez, M., Puyana, V., Lucio-Naranjo, J., Garzón, C., \& Pavón-García, I. (2019). A cost-effective approach to the evaluation of traffic noise exposure in the city of Quito, Ecuador. Case Studies on Transport Policy, 7(1), 128-137. doi: 10.1016/j.cstp.2018.12.006

[13] Cai, M., Lan, Z., Zhang, Z., \& Wang, H. (2019). Evaluation of road traffic noise exposure based on high-resolution population distribution and grid-level noise data. Building and Environment, 147(June 2018), 211-220. doi: 10.1016/j.buildenv.2018.08.037

[14] Chowdhury, A. K., Debsarkar, A., \& Chakrabarty, S. (2015). Critical assessment of day time traffic noise level at curbside openair microenvironment of Kolkata City, India. Journal of Environmental Health Science and Engineering, 13:65, 1-6. doi: 10.1186/s40201-015-0219-6

[15] CPCB. (2000), The Noise Pollution (Regulation and Control) Rules of India 2000, Ministry of Environment, Forest and Climate Change - Government of India.

[16] Da Paz, E. C., \& Zannin, P. H. T. (2010). Urban daytime traffic noise prediction models. Environmental monitoring and assessment, 163(1-4), 515-529. doi.org/10.1007/s10661-009-0854-4

[17] Das, P., Talukdar, S., Ziaul, S., Das, S., \& Pal, S. (2019). Noise Mapping and Assessing Vulnerability in Meso Level Urban Environment of Eastern India. Sustainable Cities and Society, 46(April), 101416. doi: 10.1016/j.scs.2019.01.001

[18] Dhawale, S. A., \& Bodhe, G. L. (2018). Assessment of Heterogeneous Road Traffic Noise in Nagpur. Archives of Acoustics, 43(1), 113-121. doi:10.24425/118086

[19] Douglas, O., \& Murphy, E. (2016). Source-based subjective responses to sleep disturbance from transportation noise. Environment International, 92-93, 450-456. doi: 10.1016/j.envint.2016.04.030

[20] EEA. (2015). The European environment state and outlook. European briefings - Noise. SOER 2015, pp. 1-4.

[21] EEA. (2017). Road traffic remains biggest source of noise pollution in Europe.

[22] Filho, J. J., Steffen, J. L., Andreasi, W. A., \& Zannin, P. H. T. (2015). Urban noise assessment based on noise mapping and measurements. Canadian Acoustics - Acoustique Canadienne, 43(1), 1826. https://jcaa.caa-aca.ca/index.php/jcaa/article/view/2651

[23] Golmohammadi, R., Abbaspour, M., Nassiri, P., \& Mahjub, H. (2009). A compact model for predicting road traffic noise. Journal of Environmental Health Science \& Engineering, 6(3), 181-186.

[24] Gopalakrishnan, S. (2011). Census of India, 2011. Provisional Population Totals Paper 2, Volume 1 of 2011. Rural - Urban Distribution of Tamil Nadu, Series 34.

[25] Goswami, S., \& Swain, B. K. (2017). Environmental Noise in India: a Review. Current Pollution Reports, 3(3), 220-229. doi: 10.1007/s40726-017-0062-8

[26] Guedes, I. C. M., Bertoli, S. R., Zannin, P. H. T. (2011). Influence of urban shapes on environmental noise : A case study in Aracaju Brazil. Science of the Total Environment, 412-413, 66-76. doi: 10.1016/j.scitotenv.2011.10.018

[27] Harding, A.-H., Frost, G. A., Tan, E., Tsuchiya, A., \& Mason, H. M. (2013). The cost of hypertension-related ill-health attributable to environmental noise. Noise and Health, 15(67), 437.

[28] Hunashal, R. B., \& Patil, Y. B. (2012). Assessment of noise pollution indices in the city of Kolhapur, India. Procedia - Social and Behavioral Sciences, 37, 448-457. doi: 10.1016/j.sbspro.2012.03.310 
[29] Ilic, P., Markic, N., \& Bjelic, L. (2018). Traffic Noise Levels in the City of Banja Luka. Quality of life, 9(July), 20-26. doi: 10.7251/QOL1801020I

[30] Langdon, F. J., \& Scholes, W. E. (1968). The Traffic Noise Index: A Method of Controlling Noise Nuisance. Building Research Station Current papers, 1-21.

[31] Laze, K. (2017). Findings from measurements of noise levels in indoor and outdoor environments in an expanding urban area : a case of Tirana. Noise mapping, (54), 45-56. doi: 10.1515/noise2017-0003

[32] Lisle, S. De. (2016). Comparison of Road Traffic Noise Prediction Models : CoRTN, TNM, NMPB, ASJ RTN. Acoustics Australia, 1-5. doi: $10.1007 / \mathrm{s} 40857-016-0061-8$

[33] Loupa, G., Katikaridis, A., Karali, D., \& Rapsomanikis, S. (2019). Mapping the noise in a Greek general hospital. Science of the Total Environment, 646, 923-929. doi: 10.1016/j.scitotenv.2018.07.315

[34] Margaritis, E., \& Kang, J. (2017). Soundscape mapping in environmental noise management and urban planning : case studies in two UK cities. Noise mapping, 87-103. doi: 10.1515/noise-20170007

[35] Melo, R. A., Pimentel, R. L., Lacerda, Di. M., \& Silva, W. M. (2015). Applicability of models to estimate traffic noise for urban roads. Journal of Environmental Health Science and Engineering, 13(1). doi: 10.1186/s40201-015-0240-9

[36] Meyer, R., Lavandier, C., Gauvreau, B., \& Benetto, E. (2017). Influence of the search radius in a noise prediction software on population exposure and human health impact assessments. Applied Acoustics, 127, 63-73. doi: 10.1016/j.apacoust.2017.05.028

[37] Morillas, J. M. B., Gozalo, G. R., González, D. M., Moraga, P. A., \& Vílchez-Gómez, R. (2018). Noise pollution and urban planning. Current Pollution Reports, 4(3), 208-219.

[38] Murphy, E., \& King, E. (2014). Environmental noise pollution: Noise mapping, public health, and policy. Newnes.

[39] Nassiri, P., Dehrashid, S. A., \& Hashemi, M. (2013). Traffic Noise Prediction and the Influence of Vehicle Horn Noise. Journal of Low Frequency Noise, Vibration and Active Control, 32(4), 285-291. doi: 10.1260/0263-0923.32.4.285

[40] Oyedepo, O. S., \& Saadu, A. A. (2010). Evaluation and analysis of noise levels in Ilorin metropolis , Nigeria. Environ Monit Assess, 160, 563-577. doi: 10.1007/s10661-008-0719-2

[41] Ozkurt, N., Sari, D., Akdag, A., Kutukoglu, M., \& Gurarslan, A. (2014). Modeling of noise pollution and estimated human exposure around İstanbul Atatürk Airport in Turkey. Science of the Total Environment, 482-483, 486-492. doi: 10.1016/j.scitotenv.2013.08.017

[42] Paiva, K. M., Cardoso, M. R. A., \& Zannin, P. H. T. (2019). Exposure to road traffic noise : Annoyance, perception and associated factors among Brazil's adult population. Science of the Total Environment, 650, 978-986. doi: 10.1016/j.scitotenv.2018.09.041

[43] Pathak, V., Tripathi, B. D. Ã., \& Mishra, V. (2008). Evaluation of traffic noise pollution and attitudes of exposed individuals in working place. Atmospheric Environment, 42, 3892-3898. doi: 10.1016/j.atmosenv.2007.12.070

[44] Paunovi, K., Jakovljevi, B., \& Belojevi, G. (2009). Predictors of noise annoyance in noisy and quiet urban streets, 407, 37073711. doi: 10.1016/j.scitotenv.2009.02.033

[45] Paviotti, M., \& Vogiatzis, K. (2012). Science of the Total Environment $\mathrm{On}$ the outdoor annoyance from scooter and motorbike noise in the urban environment. Science of the Total Environ- ment, The, 430, 223-230. doi: 10.1016/j.scitotenv.2012.05.010 [46] Rajakumara, H. N., \& Gowda, R. M. M. (2008). Road traffic noise prediction models: A review. International Journal of Sustainable Development and Planning, 3(3), 257-271. doi: 10.2495/SDP-V3N3-257-271

[47] Selman, H. M. (2018). Noise Pollution in Urban Environments : a Study in Al-Samawah City, Al - Muthanna, Iraq. Pollution, 81(July), 31551-31558.

[48] Seong, J. C., Park, T. H., Ko, J. H., Chang, S. I., Kim, M., Holt, J. B., \& Mehdi, M. R. (2012). Modeling of road traffic noise and estimated human exposure in Fulton County, Georgia, USA. Environment International, 37(8), 1336-1341. doi: 10.1016/j.envint.2011.05.019

[49] Singh, B., \& Choudhary, M. P. (2017). Evaluation of Noise Levels and Ascertaining Noise Indices in an Urbanizing City of Kota, Rajasthan, India. Nature Environment and Pollution Technology, 16(4), 935-938.

[50] Skarlatos, D., \& Zakinthinos, T. (2007). A simplified model for urban traffic noise prediction. Noise Control Engineering Journal, 55(2), 266-74. doi: 10.3397/1.2711615

[51] Smiraglia, M., Benocci, R., Zambon, G., Roman, H. E., \& Access, O. (2016). Predicting Hourly Traffic Noise from Traffic Flow Rate Model : Underlying Concepts for the DYNAMAP Project. Noise mapping, 130-139. doi: 10.1515/noise-2016-0010

[52] Steele, C. (2001). A critical review of some traffic noise prediction models. Applied Acoustics, 62, 271-287. doi: 10.1016/S0003682X(00)00030-X

[53] Suárez, E., \& Barros, J. L. (2014). Traffic noise mapping of the city of Santiago de Chile. Science of the Total Environment, 466-467, 539-546. doi: 10.1016/j.scitotenv.2013.07.013

[54] Sumit, K., \& Koshta, M. K. (2018). Assessment of Vehicular Noise Pollution at Different Squares in Jabalpur City, MP (India). International Research Journal of Engineering and Technology, 5(3), 2534-2537.

[55] Swain, B. K., Panda, S. K., \& Goswami, S. (2012). Dynamics of road traffic noise in Bhadrak city, India. Journal of Environmental Biology, 33, 1087-1092.

[56] Szwarc, M., Kostek, B., Kotus, J., \& Szczodrak, M. (2016). Problems of Railway Noise - A Case Study Problems of Railway Noise - A Case Study. International Journal of Occupational Safety and Ergonomics, 17(3), 309-325. doi: 10.1080/10803548.2011.11076897

[57] The European Parliament and the Council of the European Union, 2002. Directive 2002/49/EC of the European Parliament and of the Council of 25 June 2002 Relating to the Assessment and Management of Environmental Noise. Official Journal of the European Communities, Bruxelles, Belgium

[58] Tobías, A., Recio, A., Díaz, J., \& Linares, C. (2015). Health impact assessment of traffic noise in Madrid (Spain). Environmental Research, 137, 136-140. doi:10.1016/j.envres.2014.12.011

[59] Vellore Statistics. (2017). Deputy director of statistics, District statistical handbook 2016 - 2017, Vellore.

[60] Vijay, R., Sharma, A., Chakrabarti, T., \& Gupta, R. (2015). Assessment of honking impact on traffic noise in urban traffic environment of Nagpur, India. Journal of Environmental Health Science and Engineering, 13 (10), 1-9. doi: 10.1186/s40201-015-0164-4

[61] Wang, H., Chen, H., \& Cai, M. (2018). Evaluation of an urban traffic Noise-Exposed population based on points of interest and noise maps: The case of Guangzhou. Environmental Pollution, 239(August), 741-750. doi: 10.1016/j.envpol.2017.11.036 
[62] WHO. (1999). Guidelines for community noise. WHO, Geneva. 1999. Available at: http://www.who.int/docstore/peh/noise/ guidelines2.html (Accessed 6 February 2015).

[63] WHO. (2009). Night noise guidelines for Europe. http://www. euro.who.int/_data/assets/pdf_file/0017/43316/E92845.pdf

[64] WHO. (2011). Burden of disease from environmental noise. doi: http://www.euro.who.int/_data/assets/pdf_file/0008/ 136466/e94888.pdf

[65] WHO. (2018). Deafness and hearing loss. Accessed on 02.03.2019. https://www.who.int/news-room/fact-sheets/de tail/deafness-and-hearing-loss.
[66] Zannin, P. H. T., \& de Sant'Ana, D. Q. (2011). Noise mapping at different stages of a freeway redevelopment projectA case study in Brazil. Applied Acoustics, 72(8), 479-486. doi: 10.1016/j.apacoust.2010.09.014

[67] Zannin, P. H. T., Engel, M. S., Fiedler, P. E. K., \& Bunn, F. (2013). Characterization of environmental noise based on noise measurements, noise mapping and interviews : A case study at a university campus in Brazil. Cities, 31(April), 317-327. doi: 10.1016/j.cities.2012.09.008

[68] Zannin, P. H. T., \& Ferraz, F. (2016). Assessment of Indoor and Outdoor Noise Pollution at a University Hospital Based on Acoustic Measurements and Noise Mapping. Open Journal of Acoustics, 6(4), 71-85. doi: 10.4236/oja.2016.64006 


\section{Supplementary Materials}

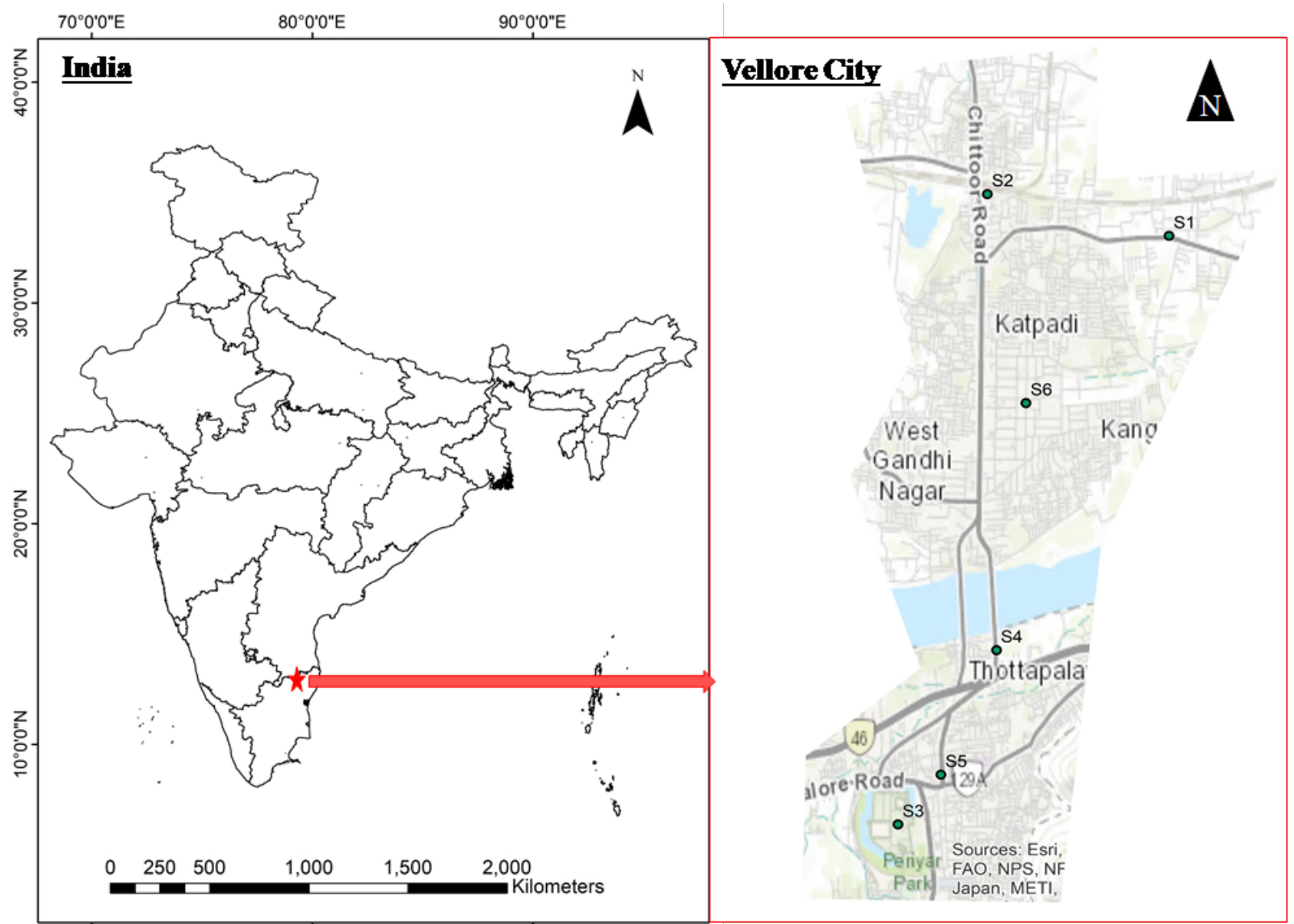

Supplementary Figure S1: Map showing study area and location of sampling points (S1 to S6)

Supplementary Table S1: Input values and correction factors given in CoRTN model

\begin{tabular}{cccccccccccccc}
\hline $\begin{array}{c}\text { Monitoring } \\
\text { Site }\end{array}$ & $\mathbf{9}$ & $\mathbf{V}$ & $\mathbf{P}$ & $\mathbf{G}$ & $\boldsymbol{V}$ & $\mathbf{D}$ & $\boldsymbol{\theta}$ & $\mathbf{L}_{\mathbf{o}}$ & $\mathbf{L ~ v}$ & $\mathbf{C} \mathbf{L}_{\mathbf{p v}}$ & $\mathbf{L}_{\mathbf{g}}$ & $\mathbf{L}_{\mathbf{d}}$ & $\mathbf{L}_{\boldsymbol{\theta}}$ \\
\hline S1 & 1983 & 50 & 0.27 & 1.8 & 48.674 & 8.630 & 171.36 & 75.373 & 1.325 & -2.833 & 0.54 & 1.943 & -0.214 \\
S2 & 315 & 50 & 0.09 & 1.8 & 48.682 & 4.176 & 163.3 & 67.383 & 1.318 & -2.911 & 0.54 & 5.096 & -0.423 \\
S4 & 2753 & 50 & 0.45 & 1.8 & 48.667 & 4.176 & 163.3 & 76.798 & 1.333 & -2.756 & 0.54 & 5.096 & -0.423 \\
S5 & 4225 & 50 & 0.18 & 1.8 & 48.678 & 4.176 & 163.3 & 78.658 & 1.321 & -2.872 & 0.54 & 5.096 & -0.423 \\
S6 & 983 & 50 & 0.36 & 1.8 & 48.671 & 4.176 & 163.3 & 72.326 & 1.329 & -2.794 & 0.54 & 5.096 & -0.423
\end{tabular}

Where, $\mathrm{Q}=$ hourly traffic volume of LV \& HV; $\mathrm{P}=\%$ of heavy vehilcles per hour; $\mathrm{V}=$ mean velocity of vehicles; $\mathrm{G}=$ gradient of the impervious bituminous road; $\boldsymbol{V}$ = corrected vehicle speed after gradient; D' = shortest slant height distance; $\mathrm{G}$ = gradient of the impervious bituminous road; $\mathrm{L}_{o}=$ basic noise emission level; $\mathrm{L}_{v}=$ correction for speed of $\mathrm{HV} ; \mathrm{CL}_{p v}=$ correction for $\%$ of $\mathrm{HV}$ with gradient; $\mathrm{L}_{g}=$ correction for gradient; $\mathrm{L}_{d}=$ correction for distance $\mathrm{b} / \mathrm{w}$ source and receiver; $\mathrm{L}_{\theta}=$ correction for angle of view 
Supplementary Table S2: Average noise level $(\mathrm{dB}(\mathrm{A}))$ measured at six sampling locations

\begin{tabular}{|c|c|c|c|c|c|c|}
\hline \multirow[t]{2}{*}{ Time } & \multicolumn{2}{|c|}{ S1 } & \multicolumn{2}{|c|}{ S2 } & \multicolumn{2}{|c|}{ S3 } \\
\hline & Weekday & Weekend & Weekday & Weekend & Weekday & Weekend \\
\hline Morning & $65.91 \pm 4.64$ & $66.69 \pm 4.13$ & $68.03 \pm 5.36$ & $67.19 \pm 4.94$ & $56.64 \pm 4.33$ & $55.81 \pm 4.77$ \\
\hline Afternoon & $66.79 \pm 3.90$ & $69.17 \pm 4.48$ & $66.96 \pm 4.32$ & $69.34 \pm 4.96$ & $56.88 \pm 4.61$ & $58.76 \pm 5.23$ \\
\hline Evening & $67.41 \pm 4.21$ & $68.63 \pm 3.91$ & $68.52 \pm 4.95$ & $68.76 \pm 5.12$ & $57.52 \pm 4.08$ & $63.39 \pm 5.96$ \\
\hline \multirow[t]{2}{*}{ Time } & \multicolumn{2}{|c|}{ S4 } & \multicolumn{2}{|c|}{ S5 } & \multicolumn{2}{|c|}{ S6 } \\
\hline & Weekday & Weekend & Weekday & Weekend & Weekday & Weekend \\
\hline Morning & $77.23 \pm 4.53$ & $74.81 \pm 4.59$ & $77.94 \pm 4.14$ & $75.32 \pm 4.45$ & $66.40 \pm 6.25$ & $68.06 \pm 5.46$ \\
\hline Afternoon & $76.58 \pm 4.48$ & $75.01 \pm 4.07$ & $77.16 \pm 4.41$ & $76.39 \pm 4.65$ & $65.39 \pm 6.05$ & $65.95 \pm 6.06$ \\
\hline Evening & $76.53 \pm 4.27$ & $74.19 \pm 3.90$ & $78.41 \pm 4.40$ & $75.63 \pm 4.50$ & $67.58 \pm 5.24$ & $66.46 \pm 5.73$ \\
\hline
\end{tabular}

